\title{
CD Review: Deep Blue C Force
}

\section{Adam Walters \\ University of Trinidad and Tobago ${ }^{1}$}

\section{ABSTRACT}

Review of the C Force's CD Deep Blue, released in December 2013 by Lucky Seven Records, (Christine Gangelhoff, flute; Christian Justilien, euphonium; Christy Lee, piano). Liner notes by Christy Lee, produced by Terry Manning.

\section{INTRODUCTION}

The Caribbean is well known for the indigenous musical forms that evolved during the region's colorful and frequently troubled history. Mass migration resulting from the slave trade threw together the musical traditions of Africa, Europe and North America resulting in styles such as Junkanoo (The Bahamas), reggae (Jamaica) and soca (Trinidad) to name just a few that have become widely popular today. Far less known, however, is the small yet significant repertoire of "art music" written by composers living and working in the region. The term art music here refers to music written in the tradition of Western classical music, with its associated musical values and performance context, and/or music written for instruments associated with this tradition. Whilst it is recognized that the term may be controversial, it is used here for practical purposes. Discussion of terminology is beyond the scope of this CD review.

Thanks to the tenacious work of Christine Gangelhoff, Assistant Professor of Music at the College of The Bahamas, who has spent years compiling lists of works from the area, the repertoire of Caribbean art music is now beginning to gain wider respect and recognition. With events such as the International Symposium on Composers of African and Afro-Caribbean Descent hosted in Nassau by Gangelhoff and the College of The Bahamas in February 2013, there is a new sense of collective identity amongst the region's composers that is yielding tangible results such as the $\mathrm{CD}$ reviewed here.

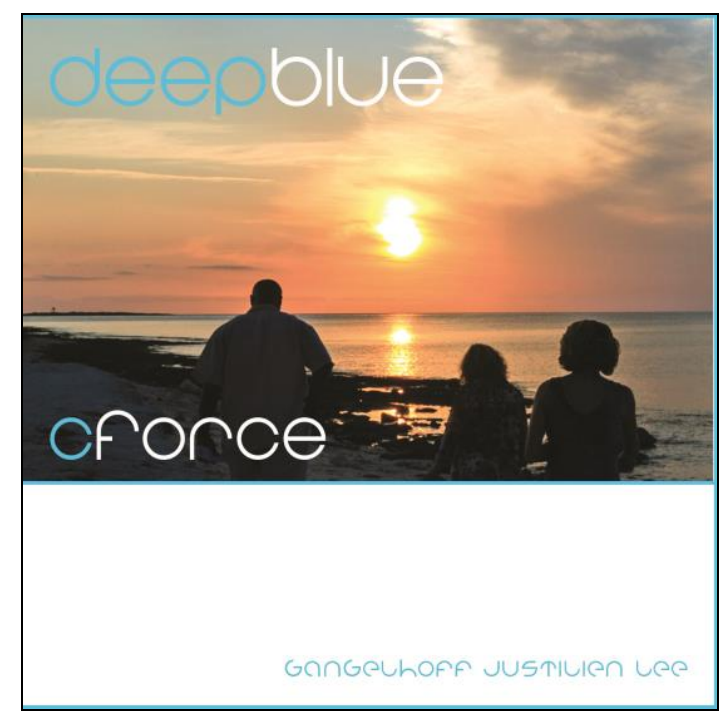

${ }_{1}^{1}$ Adam Walters, Assistant Professor, Music, Academy for the Performing Arts, University of Trinidad and Tobago, Port of Spain, Trinidad and Tobago.

E-mail: adam.walters@utt.edu.tt

APA reference: Walters, A. (2014). CD review: Deep Blue ; C Force. International Journal of Bahamian Studies, 20(1), 76-78. https://doi.org/10.15362/ijbs.v20i1.223

(C) A. Walters, 2014. Journal compilation @ The International Journal of Bahamian Studies, 2014 
The Bahamas is notable for the already substantial catalogue of art music by local composers. There are the operas Our Boys (1986) by Cleophas Adderley, Gerda and the Soldier (2010) by Quincy Parker and The Legend of Sammie Swain (1971) by Edward Clement Bethel (De Lerma, 2013). Parker has written several orchestral works and there have been many recent contributions to the chamber and choral music repertoires by Bahamian composers such as Franz Hepburn, Christian Justilien and long-time Bahamian resident Terry Manning, all of whom have works featured on Deep Blue, C Force's latest album.

C Force is a trio made up of flute, euphonium and piano. This unusual (and unexpectedly successful) combination of so-called classical instruments is the happy result of circumstance. Identifying the need to promote locally-composed music, members of the music faculty of the College of The Bahamas formed a trio, and these happened to be the instruments played by the three music professors there. $^{2}$ With Christine Gangelhoff on flute, Christian Justilien on euphonium and Christy Lee on piano, the group's repertoire consists of arrangements of local traditional music and of original works.

Between them, the players of $\mathrm{C}$ Force boast an impressive $\mathrm{CV}$ : Gangelhoff has enjoyed a busy performance schedule in the United States, having worked with orchestras including the Minnesota Orchestra and the Oregon Symphony and also with groups focusing on Celtic, klezmer and reggae-ska repertoires. Lee, also American, has worked

\footnotetext{
${ }^{2}$ Another instance of an unusual instrumental ensemble in the Caribbean is the Ibis Ensemble of the University of Trinidad and Tobago whose unconventional instrumentation, like that of $C$ Force, is the result of circumstance rather than design. Each group therefore has a distinct voice affording composers in the region the opportunity to express aspects of local cultures through a different type of musical lens.
}

as coach, pianist and conductor with many major United States orchestras and opera companies. Justilien, the Bahamian of the trio, has been well-known nationally for many years as a brass instrument specialist, music educator, composer and Junkanoo band leader. In addition to their credentials as performers, all three members of C Force also have distinguished academic careers (De Lerma, 2013).

Whilst C Force's first release Tchaka Mizik (2010) gives listeners a broad overview of the group's scope (it includes original music by $\mathrm{C}$ Force member Justilien as well as transcriptions both of regional traditional music and European operatic arias), Deep Blue is a $\mathrm{CD}$ with a more clearly defined raison d'être. As stated in the CD's liner notes:

Deep Blue is a reflection of C Force's commitment to the preservation and promotion of art music from The Bahamas and the neighboring Caribbean region. It is a compilation of original compositions, transcriptions, and arrangements of pieces written in a classical vein while manifesting elements of Bahamian folk culture in the use of theme, rhythm, and melody. As The Bahamas celebrates its 40th year of independence, Deep Blue features a combination of works by Bahamian composers as well as pieces inspired by the islands of The Bahamas and their surrounding waters.

The music-making on all tracks of Deep Blue is exemplary, and the musical chemistry between the players results in tightly fused ensemble playing throughout. One might expect the heavy brass tones of the euphonium to be overly dominant, but in fact the balance between the three musicians is beautifully managed, with each member of the trio clearly sensitive to their changing roles 
within each piece, at times as melodic lead, and elsewhere as background accompanist. Despite some additional percussion added to some tracks and an overdubbed tuba part in Justilien's piece, "Tilla" (track 6) all tracks were recorded live, and producer Terry Manning has ensured that the recordings are crisp and clear at all times.

Evidently enjoying the different musical flavors of their selections, the musicians respond with an impressively varied palette of musical colors that ensures that the $\mathrm{CD}$ never slips into monotony. Gangelhoff's flute sparkles with virtuosity in the trio's arrangement of Parker's "The Kindly Ones Waltz" (track 3). With its arrestingly angular melody reminiscent of Prokofiev, this is a gift of a flute part. And Gangelhoff brings a touching sensitivity to Terry Manning's beautifully heart-felt "The Silent Sea" (track 4) with its Rachmaninov-like sense of cadence. This nocturne for flute and piano duo is a particularly attractive addition to the repertoire.

Lee displays an equally impressive range of emotion on piano. Playing almost constantly throughout the $\mathrm{CD}$, she represents the backbone of the ensemble. Highlights from Lee on this disc include her expressive, even impassioned playing in Hepburn's "Bahama Moon" (track 2), and the delicate yet rich sonority she finds for the gently rippling arpeggios at the start of Justilien's "Ragged Island" (track 10).

Justilien's euphonium playing is sonorous and sensitive, with forte passages always appropriately judged for the small-scale ensemble. As C Force's composer-in- residence Justilien has a unique perspective on writing new music for the group. He has a facility for writing memorable melodies underpinned by Bahamian rhythms, but is arguably at his best when he tries something new. In "Eleuthera: Da Bight" (track 9) for example, the inspired combination of low flute and high euphonium is a captivating texture. And the enigmatic ending of the vividly programmatic "Ragged Island: Deep South" (track 10) is a risk that pays dividends, ensuring that the movement (and the tragedy that inspired it) lingers in the memory long after the suite has finished.

Included on the disc are readings by Marion Bethel, whose poetry was inspired by Justilien's Bahama Islands Suite. The Bahamian poet's voice is heard over musical extracts of the suite (tracks 12-16). Collaborations of this nature always add layers of meaning to the resulting work, though in this instance the music is too enticingly melodic to act as an unobtrusive backdrop.

Much of the charm of this disc stems from its sincerity. The committed, communicative performances confirm the musicians of $\mathrm{C}$ Force as pioneers in promoting new Bahamian compositions. With art music from the Caribbean finally being recognized as a significant repertoire in its own right, Deep Blue is a timely release. Top-level performances of new pieces-some true treasures amongst them-ensure that this CD is an excellent record of art music currently being written in The Bahamas.

\section{REFERENCES}

De Lerma, D.-R. (2013, December). Deep

Blue by C Force [Review]. Retrieved from http://africlassical.blogspot.com/2013/12/d ominique-rene-de-lerma-deep-blue-by.html 